\title{
Determination of Optimal Number of Relays Using a New Energy Model for WSN
}

\author{
Shilpi ${ }^{1}$, Nupur Pal ${ }^{2}$ and Partha Pratim Bhattacharya ${ }^{3}$ \\ Department of Electronics and Communication Engineering \\ Faculty of Engineering and Technology \\ Mody Institute of Technology \& Science (Deemed University) \\ Lakshmangarh, Rajasthan - 332311, India. \\ 1 shilpi3gupta@gmail.com
2 lucky.nupur@gmail.com
${ }^{3}$ hereispartha@gmail.com
}

ABSTRACT

Wireless Sensor Networks are proving themselves as a boon to the surroundings and its deployment in a prominent area is to be considered for minimum energy consumption. In this paper, we have considered deployment of a sensor grid network for 36 and 100 number of sensor nodes. Diagonally opposite nodes are considered to be source and destination. Using a modified energy model, the energy consumption for direct path and that with different number of relays are calculated. The maximum distance up to which direct transmission is possible and the number of required relays for higher transmission distances are then found out.

\section{General Terms}

Wireless Sensor Network

\section{Indexing terms}

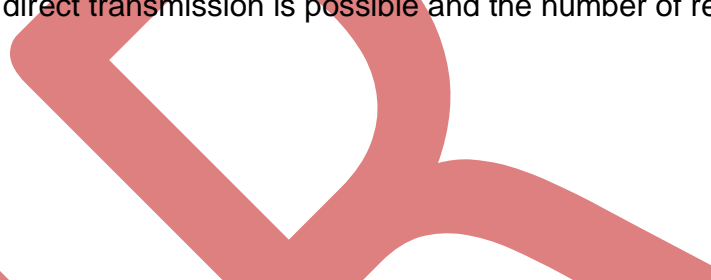

Wireless Sensor Network, relay nodes, node deployment, energy consumption, maximum distance of transmission, path loss exponent

\section{INTRODUCTION}

A sensor network is an infrastructure comprised of sensing, computational and communication elements that give an administrator the ability to instrument observe and react to the events and phenomenon in a specified environment. There are four basic components in a sensor network like an assembly of distributed or localized sensors, an interconnected network, a central point of information clustering ,a set of communication resources at the central point to handle data correlation and event trending etc. In Wireless sensor network (WSN) the sensor nodes are used \& they are also called as motes (very small in size) which are used to transmit information from once place to another place like from one node to an another node [1]. Sensors are interconnected via a series of multi-hop short-distance low power wireless link. Power consumption is a prominent issue to be considered as a design constraint. Here we are taking into consideration the fact such as Energy consumption in a sensor network up to a certain distance [2]. The lifetime of a sensor node is very less so it is efficient to transmit the information from one sensor node to an another node [3-6].The sensor nodes also use sleep \& idle modes for the sake of an efficient battery.

Sensor nodes have many applications \& thus so are used in many areas like in military, Intelligent home, Atmospheric conditions detection (e.g. temperature, humidity, pressure, sound, light) in inventory control, and in disaster management etc. Placement of the sensor nodes in these applications is random in nature or these can be placed manually. For example in military, a large number of sensors are dropped from a helicopter to the required place from where they want to fetch information.

A sensor node contains a sensing unit, processing unit, transceiver unit, \& power unit [7]. Sensor nodes do tasks like processing, radio transmission-reception, sensing and actuating. In this paper we are discussing the power consumption and the maximum distance of transmission using relay nodes in a square area grid network of $6 * 6$ and $10^{*} 10$ dimensions. The structural view of sensor network is shown in Figure 1. 
Council for Innovative Research www.cirworld.com
International Journal of Computers \& Technology

Volume 4 No. 2, March-April, 2013, ISSN 2277-3061

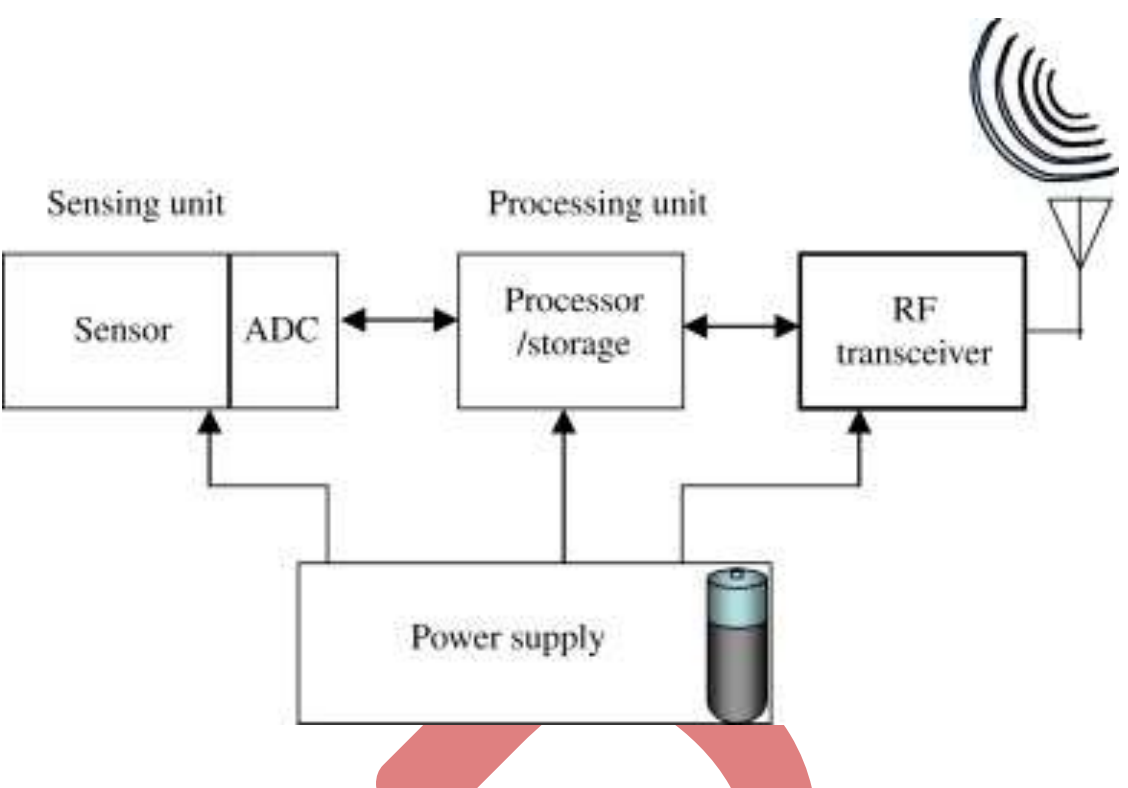

Figure 1. Structural view of a Sensor Network.

\section{ENERGY MODELING FOR WSN}

As in wireless sensor network, one sensor node can transmit the information via two ways: One by direct link \& second by node to node delivery .In second case the number of relay nodes can be used which results into reduce in the power consumption required for the transmission to transmit a data from the source node to the destination node these relay nodes will act as a router which receive the data, amplify the data signal and forward it to next neighbor. Receiving, amplifying, and forwarding of the data can be expressed by the following models $[8,9,10,11]$.

Now, transmitted power can be expressed as:

$\operatorname{Etx}(\mathrm{k}, \mathrm{d})=$ Etxelec $\times \mathrm{K}+\varepsilon a m p \times K \times d^{\mathrm{n}}$

Received power can be expressed as:

$\operatorname{Erx}(\mathrm{K})=$ Erxelec $\times \mathrm{K}$

where:

Etx $(\mathrm{k}, \mathrm{d})$ : Power consumption to transmit $K$ bits of data to distance $\mathrm{d}$

$\operatorname{Erx}(K)$ : Power consumption to receive $K$ bits of data

Erxelec : Power consumption in the sensor node receiver circuit to process 1 bit

Etxelec : Power consumption in the sensor node transmitter circuit to process 1 bit

Eamp: Power consumption by amplifier

K: Data size in bits

$\mathrm{d}$ : Distance between the two nodes

$\mathrm{n}$ is the path loss exponent

$\mathrm{N}$ : Total number of nodes in the network

$\mathrm{d}_{\text {dimension: }}$ The distance from the first node to the last node in the same row/column (in meters).

\section{PROBLEM FORMULATION}

Here, for $6 \times 6$ and $10 \times 10$ networks, it is assumed that:

Eamp $=100 \mathrm{pJ} / \mathrm{bit} / \mathrm{m}^{2}$

Erxelec $=50 \mathrm{~nJ} / \mathrm{bit}$

Etxelec $=50 \mathrm{~nJ} / \mathrm{bit}$ and

$\mathrm{K}=500$ bits

$\mathrm{n}=4$, considering suburban area. 
Here, we have used equations (1) and (2) \& taken into consideration the source node and destination node as the two farthest nodes in a grid network receiving data along the diagonal path [12].

\section{Analysis of $6 \times 6$ Area Grid WSN Network}

Here, node 1 is the source node \& node 36 is the destination node as shown in Figure 2. The transmission from node 1 to node 2 along a diagonal path can be done by using several cases as discussed below:

Case 1: Direct path from node 1 to node 36 without using any relay, the distance calculated from node 1 to node 36 is $\sqrt{2} d_{\text {dimension: }}$

In general, $E_{\text {tot }}(6 \times 6)=($ Transmitted power $)+($ Amplified Power $)+($ Received Power $)$

So, $E_{\text {tot }}(6 \times 6)$ direct $=(50 \times 500)+0.1 \times\left(\sqrt{ } 2 d_{\text {dimension })}{ }^{4} \times 500+50 \times 500\right.$

Thus we get, $E_{\text {tot }}(6 \times 6)=50,000+200 d_{\text {dimension }}{ }^{4}$

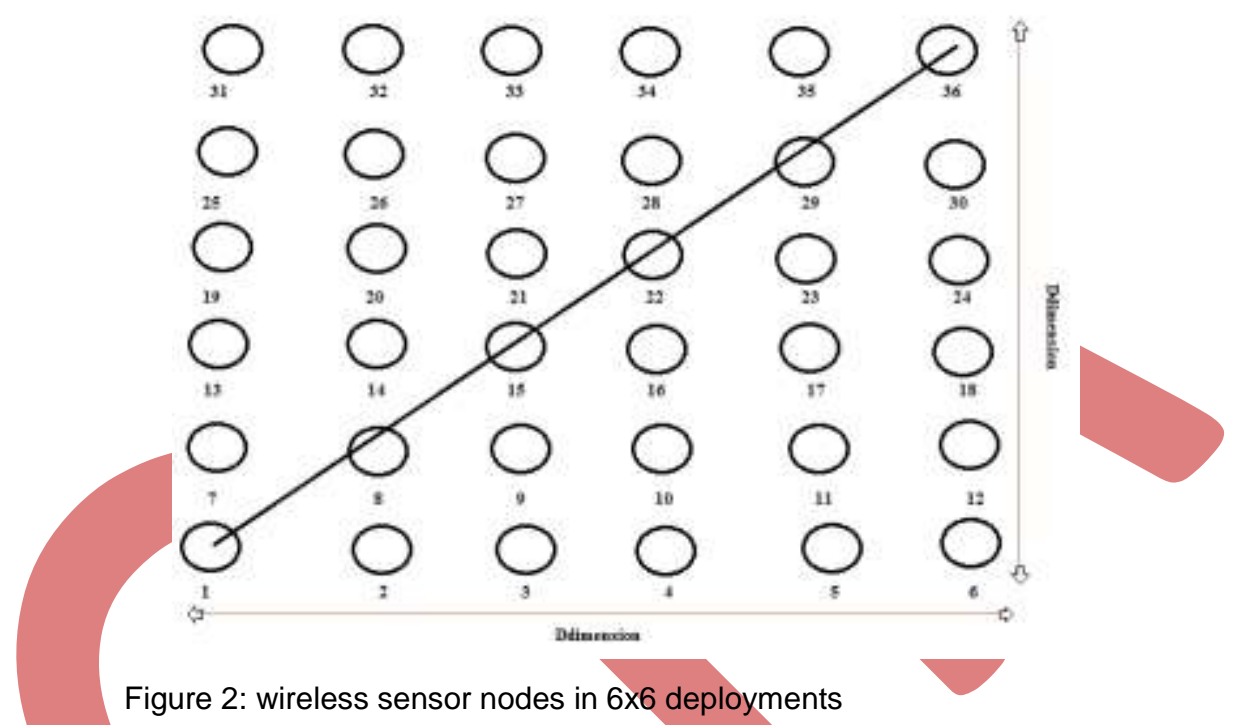

Case2: By using relay nodes:

\section{* Using one relay :}

Either Node 8 or Node 29 is taken as relay. Now the data is transmitted from Node 1 to Node $8 \&$ then from Node 8 to Node 36 \& similarly for node 29 . So the total power consumption after applying equations (1) and (2) is:

$E_{\text {tot }} 6 \times 6=50 \times 500 \times 2+0.1 \times\left(\sqrt{ } 2 d_{\text {dimension }} / 5\right)^{4} \times 500+0.1 \times\left(4 \sqrt{ } 2 d_{\text {dimension }} / 5\right)^{4} \times 500+50 \times 500 \times 2$

$E_{\text {tot }}(6 \times 6)=82.24 d_{\text {dimension }}{ }^{4}+100,000$

Or, if either Node 15 or Node 22 is taken as relay nodes then the data is transmitted from Node 1 to Node 15 \& then Node 15 to Node 36 \& similarly for node 22 . Hence the total power consumption after applying equations (1) and (2) is:

$E_{\text {tot }} 6 \times 6=50 \times 500 \times 2+0.1 \times\left(2 \sqrt{ } 2 d_{\text {dimension }} / 5\right)^{4} \times 500+0.1\left(3 \sqrt{ } 2 d_{\text {dimension }} / 5\right)^{4} \times 500+50 \times 500 \times 2$

$E_{\text {tot }} 6 \times 6=31.04 d_{\text {dimension }}{ }^{4}+100,000$

Case 3:

\section{* Using two relays :}

Taking the pair of nodes like Node $(8,15)$, the data gets transmitted from node 1 to node 8 \& then to node 15 and finally to node 36 . Similar transmission is considered with $(8,29)$ or $(22,29)$. So the total power consumption after applying equations (1) and (2) is:

$E_{\text {tot }}(6 \times 6)=50 \times 500 \times 3+(0.1) \times 2\left(\sqrt{ } 2 d_{\text {dimension }} / 5\right)^{4} \times 500+0.1 \times\left(3 \sqrt{ } 2 d_{\text {dimension }} / 5\right)^{4} \times 500+50 \times 500 \times 3$

$E_{\text {tot }}(6 \times 6)=26.56 d_{\text {dimension }}{ }^{4}+150,000$

From the above equation (5), we can conclude that relay at mid position consumes lower power. 


\section{Analysis of $10 \times 10$ area grid WSN network}

Here, node 1 and 100 are the source node \& destination node respectively, as shown in Figure 3 . The transmission of the data from source node to destination node along diagonal path can be done by using several cases as followed:

Case 1: Direct transmission from node 1 to node 100 without using any relay

Etot $(10 \times 10)=50 \times 500+0.1 \times\left(\sqrt{ } 2 d_{\text {dimension }}\right)^{4} \times 500+50 \times 500$

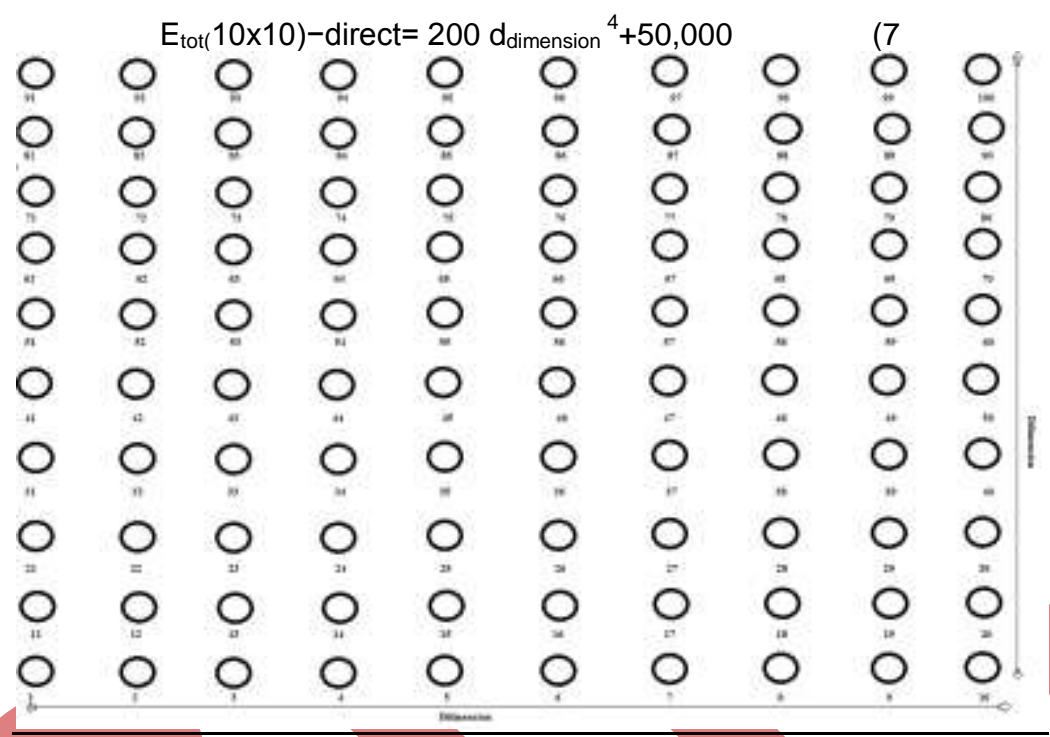

Figure3: wireless sensor nodes in $10 \times 10$ deployments

\section{Case2:}

\section{* Using one relay:}

We have taken either Node 45 or Node 56 as single relay node. This means we transmit data from Node 1 to Node 45 and then Node 45 to Node 100; similarly for node 56 also.

So the total power consumption after applying Equations (1) and (2) is:

$E_{\text {tot }}(10 \times 10)=50 \times 500 \times 2+(0.1) \times\left(4 \sqrt{ } 2 d_{\text {dimension }} / 9\right)^{4} \times 500+0.1 \times\left(5 \sqrt{ } 2 d_{\text {dimension }} / 9\right)^{4} \times 500+50 \times 500 \times 2$

$E_{\text {tot }}(10 \times 10)=26.85 d_{\text {dimension }}{ }^{4}+100,000$

Case3:

\section{* Using two relays:}

Considering the pair of nodes like $(34,67)$, the data gets transmitted from node 1 to node 34 \& then to node 67 and finally to node 100 .

So the total power consumption after applying equations (1) and (2) is:

$\mathrm{E}_{\text {tot }}(10 \times 10)=50 \times 500 \times 3+(0.1) \times\left(3 \sqrt{ } 2 \mathrm{~d}_{\text {dimension }} / 9\right)^{4} \times 500 \times 3+50 \times 500 \times 3$

$E_{\text {tot }}(10 \times 10)=7.41 d_{\text {dimension }}{ }^{4}+150,000$

The data paths for using different number of relay nodes are shown below in Table 1.

\begin{tabular}{|c|c|}
\hline $\begin{array}{l}\text { No. of Relays } \\
\text { used }\end{array}$ & Path Followed to Transmit the data \\
\hline 0 & $1 \Rightarrow 100$ \\
\hline 1 & 1ち $\Rightarrow 500$ \\
\hline 2 & $1 \sqsubset 34 \Rightarrow 7 \Rightarrow 0$ \\
\hline 3 & 1द34 द $\Rightarrow \Rightarrow$ \\
\hline
\end{tabular}




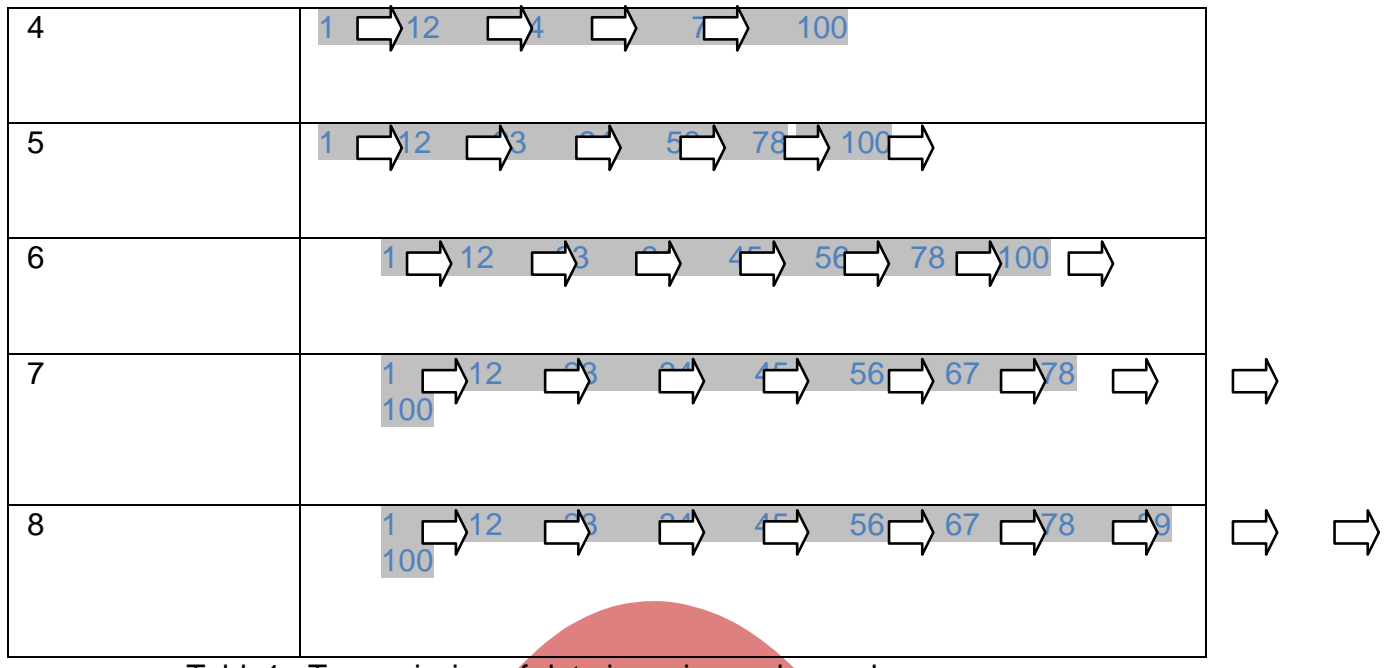

Table1. Transmission of data in various relay nodes

Case4:

\section{* Using three relays:}

Similar process in applied for $(34,56,78),(23,56,78),(23,45,78) \&(23,45,67)$.

Total power consumption after applying (1) and (2) is:

$E_{\text {tot }}(10 \times 10)=50 \times 500 \times 4+(0.1) \times\left(3 \sqrt{2} d_{\text {dimension }} / 9\right)^{4} \times 500+0.1 \times 3 \times\left(2 \sqrt{ } 2 d_{\text {dimension }} / 9\right)^{4} \times 500+50 \times 500 \times 4$

$E_{\text {tot }}(10 \times 10)=3.93 d_{\text {dimension }}{ }^{4}+200,000$

Case5:

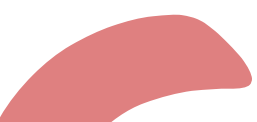

\section{* Using four relays:}

Taking four relay nodes like $(12,34,56,78)$, data are transmitted from node 1 to 12 then to 34 ; then to 56 ; then to 78 \& then to node 100 .

Similar process can be applied for these cases also: $(23,34,56,78),(23,45,56,78),(23,45,67,78),(23,45,67,89)$, $(23,56,67,78) \&(23,56,67,89)$.

So, the total power consumption after applying (1) and (2) is:

$E_{\text {tot }}(10 \times 10)=50 \times 500 \times 5+(0.1) \times 5 \times\left(\sqrt{ } 2 d_{\text {dimension }} / 9\right)^{4} \times 500+50 \times 500 \times 5$

$E_{\text {tot }}(10 \times 10)=1.98 d_{\text {dimension }}+250,000$

\section{Case6:}

\section{* Using five relays:}

Similar process can be applied for these set of five relay nodes $(12,23,34,56,78),(12,23,45,56,89),(12,23,45,67,78)$,

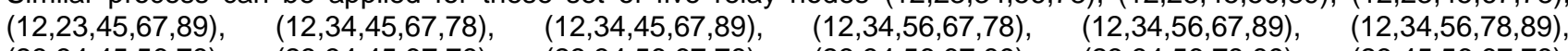
$(23,34,45,56,78), \quad(23,34,45,67,78), \quad(23,34,56,67,78), \quad(23,34,56,67,89), \quad(23,34,56,78,89), \quad(23,45,56,67,78)$, $(23,45,56,67,89),(23,45,67,78,89)$.

So the total power consumption after applying (1) and (2) is:

$E_{\text {tot }}(10 \times 10)=50 \times 500 \times 6+3 \times(0.1) \times 500 \times\left(\sqrt{ } 2 d_{\text {dimension }} / 9\right)^{4} \times+3 \times(0.1) \times 500 \times\left(2 \sqrt{2} \mathrm{~d}_{\text {dimension }} / 9\right)^{4}+50 \times 500 \times 6$

$E_{\text {tot }}(10 \times 10)=1.55$ ddimension $^{4}+300,000$

Case7:

\section{* Using Six relays:}

Similar process is applied for set of six relay nodes $(12,23,34,45,56,78)$, $(12,23,34,45,67,89),(12,23,34,56,67,78),(12,23,34,56,67,89),(12,23,34,56,78,89,(12,23,34,67,78,89),(12,23,45,56,67,78),($ $12,23,45,56,67,89),(12,23,45,56,78,89),(12,23,45,67,78,89),(23,34,45,56,67,78),(23,34,45,56,67,89),(23,34,45,56,78,89),($ $23,34,45,67,78,89),(23,34,56,67,78,89),(23,45,56,67,78,89)$.

So the total power consumption after applying (1) and (2) is: 
$E_{\text {tot }}(10 \times 10)=50 \times 500 \times 7+0.1 \times\left(\sqrt{ } 2 d_{\text {dimension }} / 9\right)^{4} \times 500 \times 5+0.1 \times\left(2 \sqrt{ } 2 d_{\text {dimension }} / 9\right)^{4} \times 500 \times 2+50 \times 500 \times 7$

$E_{\text {tot }}(10 \times 10)=1.12 d_{\text {dimension }}{ }^{4}+350,000$

Case8:

\section{* Using Seven relays:}

Similar process can be done for these relay nodes: $(12,23,34,45,56,67,78), \quad(12,23,34,45,56,67,89)$, $(12,23,34,45,56,78,89),(12,23,34,45,67,78,89),(12,23,34,56,67,78,89),(12,23,45,56,67,78,89),(12,34,45,56,67,78,89),($ $23,34,45,56,67,78,89)$.

So, the total power consumption after applying equations (1) and (2) is:

$E_{\text {tot }}(10 \times 10)=50 \times 500 \times 8+0.1 \times\left(\sqrt{ } 2 d_{\text {dimension }} / 9\right)^{4} \times 500 \times 7+0.1 \times\left(2 \sqrt{ } 2 d_{\text {dimension }} / 9\right)^{4} \times 500+50 \times 500 \times 8$

$E_{\text {tot }}(10 \times 10)=0.70 d_{\text {dimension }}{ }^{4}+400,000$

\section{Case9:}

\section{* Using eight relays:}

Similarly, for eight relay nodes $(12,23,34,45,56,67,78,89)$, total power consumption after applying (1) and (2) is:

$E_{\text {tot }}(10 \times 10)=50 \times 500 \times 9+0.1 \times\left(\sqrt{ } 2 d_{\text {dimension }} / 9\right)^{4} \times 500 \times 9+50 \times 500 \times 9$

$E_{\text {tot }}(10 \times 10)=0.27 d_{\text {dimension }}{ }^{4}+450,000$

\section{OBSERVATIONS}

Here, we have calculated the range for transmission of signal directly and using relay nodes.

Equating equations (7) \& (8), we get:

200 ddimension $^{4}+50,000=26.85 . d_{\text {dimension }}{ }^{4}+100,000$

$\mathrm{d}_{\text {dimension }}=4.12 \mathrm{~m}$

This shows that maximum distance that can be covered without using relay is $4.12 \mathrm{~m}$.

Similarly equating equations (8) \& (9)

$\mathrm{d}_{\text {dimension }}=7.12 \mathrm{~m}$

The maximum distance covered using 1 relay is $7.12 \mathrm{~m}$.

Equating equations (9) \& (10)

$\mathrm{d}_{\text {dimension }}=10.95 \mathrm{~m}$

The maximum distance covered using 2 relays is $10.95 \mathrm{~m}$.

Equating equations $(10) \&(11)$

$\mathrm{d}_{\text {dimension }}=\mathbf{1 2 . 6 5 \mathrm { m }}$

The maximum distance which may be covered using 3 relays is $12.65 \mathrm{~m}$.

Equating equations (11) and (12)

$\mathrm{d}_{\text {dimension }}=18.46 \mathrm{~m}$

The maximum distance that can be covered using 4 relays is $18.46 \mathrm{~m}$.

Equating equations (12) \& (13)

$\mathrm{d}_{\text {dimension }}=\mathbf{1 8 . 4 6 \mathrm { m }}$

The maximum distance which can be covered using 5 relays is $18.46 \mathrm{~m}$.

Equating equations (13) \& (14)

$\mathrm{d}_{\text {dimension }}=18.46 \mathrm{~m}$

The maximum distance which can be covered with 6 relays is $18.46 \mathrm{~m}$.

Equating equations (14) \& (15)

$\mathrm{d}_{\text {dimension }}=18.46 \mathrm{~m}$

The maximum distance covered using 7 relays is $18.46 \mathrm{~m}$ 
Maximum distances of transmission with different number of relay nodes are shown in Table 2.

\begin{tabular}{|c|c|}
\hline Number of relay Nodes to be used & $\begin{array}{c}\text { Maximum Distance of transmission } \\
\text { (In Meters) }\end{array}$ \\
\hline 0 (Direct transmission) & 4.12 \\
\hline 1 & 7.12 \\
\hline 2 & 10.95 \\
\hline 3 & 12.65 \\
\hline 4 & 18.46 \\
\hline 5 & 18.46 \\
\hline 6 & 18.46 \\
\hline 7 & 18.46 \\
\hline
\end{tabular}

Table 2

Hence, it is observed that in $10 \times 10$ grid network, the direct transmission is best up to distance $4.12 \mathrm{~m}$, then one relay node can be used up to distance $7.12 \mathrm{~m}$, then two relays is better for distance $10.95 \mathrm{~m}$. Similarly, it can be concluded that three relays are required for transmission upto $12.65 \mathrm{~m}$ and finally $18.46 \mathrm{~m}$ distance can be covered using 4 to 7 relay nodes but using four number of relays would be the optimum choice because energy consumption will be less.

The variation of distances with corresponding relay nodes is being shown graphically in Figure 4.

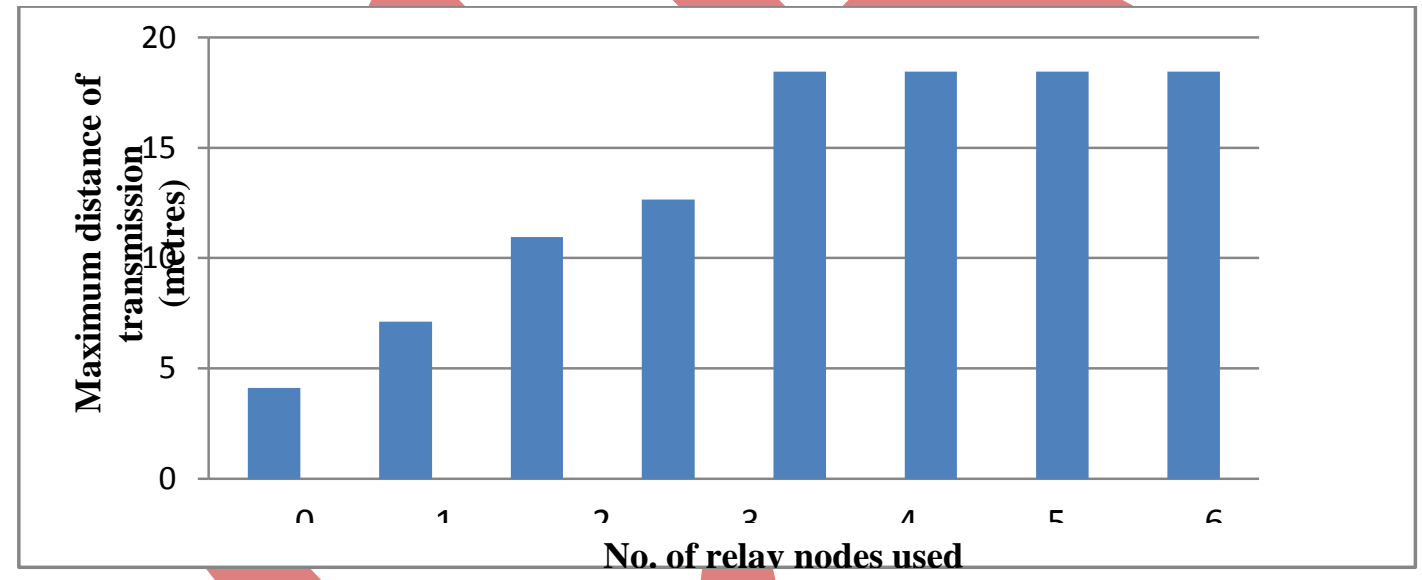

Figure 4. Maximum distance of transmission vs. number of relay nodes

From the above graph it is observed that transmission distance increases upto four number of relays and then becomes constant.

\section{CONCLUSION}

In the present work, we have considered a 10×10 wireless sensor network. It is seen that energy consumption is more in direct transmission compared to the same when transmission is done by using relays. We have calculated direct transmission range and optimal number of relays required for larger coverage area.

\section{REFERENCES}

[1] Rudranatha Mitra \& Diya Nandy, "Node deployment and the impact of relay nodes in Wireless sensor network", International Journal of Computer Science and Communication Networks, Vol. 2, No.3, pp. 358-363.

[2] R.Pandi Selvam and V. Palanisamy, "An efficient cluster based approach for multi source multicast routing protocolin mobile ad-hoc Networks", International Journal of Computer Networks and Communications (IJCNC), Vol.3,No.1,pp.154166.

[3] Apala Ray, "Planning and analysis toll for large scale deployment of wireless sensornetwork", International journal of next generation networks(IJNGN),Vol.1,No.1,pp.29-36.

[4] Wint Yi Poe \& Jens B Schmitt, "Node deployment in large Wireless sensor networks:Coverage, energy consumption, and worst case delay", Proceeding of AINTEC '09 Asian Internet Engineering Conference, New York, NY, USA: ACM, pp. 77-84. 
[5] Sivakumar Sivaramakrishnan \& Adnan Al-Anbuky, "Analysis of Network connectivity: wild life and sensor network", proceeding of Telecommunication Networks andApplications Conference (ATNAC), Australasian, pp. 1-6.

[6] Hyun-Soo Cha, Jea-Tek Ryu, Ki-Hyung Kim \& Seung-Hwa Yoo, " Efficient Relay Node displacement mechanism for improvement of lifetime in WSN", Proceeding of the $9^{\text {th }}$ International Symposium Communications and Information Technology ISCIT Conference,Icheon,, pp. 905-906

[7] Jyoti Saraswat, Neha Rathi, Partha Pratim Bhattacharya, "Techniques to Enhance Lifetime of Wireless Sensor Networks: A Survey”, Global Journal of Computer Science and Technology (E), Volume 12, Issue 14, Version 1.0, September 2012, ISSN Numbers: Online: 0975-4172, Print: 0975-4350, pp 21 - 31.

[8] Avid Avokh \& Ghasem Mirjalily "Dynamic balanced spanning Tree (DBST) For data aggregation in Wireless Sensor Network, proceeding of $5^{\text {th }}$ International symposium on Telecommunication (IST) Conference, Iran, pp. 391-396.

[9] Kunjie Xu \& Ivan Howill,"Realistic Energy Model Based Energy Balanced Optimization For low rate WPAN network”, 'SOUTHEASTCON09', IEEE, Atlanta GA, pp.261-266.

[10] Farah A. Nasser and Haider M, "Different node deployments in a square area grid of wireless sensor network and optimal number of relays", International Journal of Computer Networks \& Communications (IJCNC) Vol.4, No.6, pp. 1-17

[9] Avid Avokh \& Ghasem Mirjalily, "Dynamic balanced spanning Tree (DBST) For data aggregation in Wireless Sensor Network, proceeding of $5^{\text {th }}$ International symposium on Telecommunication (IST) Conference, Iran, pp. 391-396.

[10] Yen-Wen Chen \& Chin Shiang kuo, "Integrated Design Of Grid Based Routing in Wireless Sensor Network",Proceeding Of the $21^{\text {st }}$ International Conference on Advanced Information Networking \& Applications (AINA),Niagra Falls.pp. 625-631.

[11] Purnima K. Sharma,R.K. Singh, "Comparative Analysis of Propagation Path loss Models with Field Measured Data", International Journal of Engineering Science and Technology Vol. 2(6),pp. 1-5.

[12] Muhammed Sajjad Hussain \& Abdul Motalib, " Energy - Efficient Hierararichal Routing Protocol For Homogeneous Wireless Sensor Network”, International Journal Of computer Science \& Network Security, Vol. 11, No.11, pp.-80-86.

\section{Author' biography with Photo}

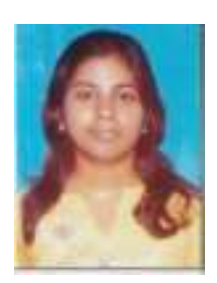

Shilpi was born in India on May 3, 1991. She received her B.Tech degree in Electronics and Communication Engineering from Mody Institute of Technology and Science (Deemed University), Rajasthan, India in 2012 and currently is a M. Tech (Signal Processing) student in the same University. Her research interest lies in Wireless Sensor Networks.

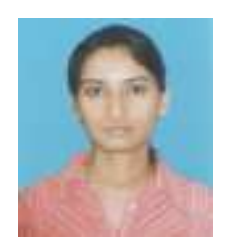

Nupur Pal was born in India on May 11, 1989. She received her B. Tech. degree in Electronics and Communication Engineering from Sanjay Institute of Engineering and Management, Uttar Pradesh Technical University (UPTU), India in 2012 and currently is a M. Tech (Signal Processing) student in Mody Institute of Technology and Science (Deemed University), Rajasthan, India. Her research interest lies in Wireless Sensor Networks.

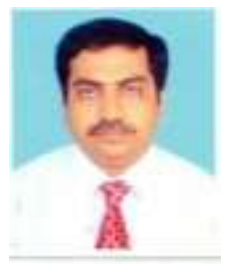

Dr. Partha Pratim Bhattacharya was born in India on January 3, 1971. He has 16 years of experience in teaching and research. He served many reputed educational Institutes in India in various positions. At present he is working as Professor in Department of Electronics and Communication Engineering in the Faculty of Engineering and Technology, Mody Institute of Technology and Science (Deemed University), Rajasthan, India. He worked on Microwave devices and systems and mobile cellular communication systems. He has published more than 90 papers in refereed journals and conferences. His present research interest includes mobile cellular communication, wireless sensor network and cognitive radio.

Dr. Bhattacharya is a member of The Institution of Electronics and Telecommunication Engineers, India and The Institution of Engineers, India. He is the recipient of Young Scientist Award from International Union of Radio Science in 2005. He is working as the chief editor, editorial board member and reviewer in many reputed journals. 